\title{
Effect of Perinatal Alcohol Exposure on Ibotenic Acid-Induced Excitotoxic Cortical Lesions in Newborn Hamsters
}

\author{
CHRISTINE ADDE-MICHEL, OLIVIER HENNEBERT, VINCENT LAUDENBACH, \\ STÉPHANE MARRET, AND PHILIPPE LEROUX \\ UPRES EA 2122 [C.A.-M., O.H., V.L., S.M., P.L.], School of Medicine and Pharmacy, Rouen University, \\ F-76183 Rouen, France, Department of Neonatal Medicine [C.A.-M., V.L., S.M.], Rouen University \\ Hospital, F-76031 Rouen, France
}

\begin{abstract}
Alcohol is one of the most common noxious substance to which fetuses are exposed. The aim of the study was to determine the effects of in utero alcohol exposure on excitotoxin-induced neuronal migration disorders. Female hamsters received alcohol (7\%) for 3-5 mo or for the last 9-12 d of gestation. Alcohol diet was continued for $5 \mathrm{~d}$ during lactation in both groups. Drinking behavior was monitored. Peak plasma alcohol levels were $104 \pm$ $12 \mathrm{mg} / \mathrm{dL}$ and $225 \pm 6 \mathrm{mg} / \mathrm{dL}$ after $30 \mathrm{~min}$ for hamsters receiving an intragastric dose of $3 \mathrm{~mL}$ or $5 \mathrm{~mL}$ alcohol, respectively. At birth, pups received intrapallial injections ibotenic acid ( $1 \mathrm{ng}, 100 \mathrm{ng}$, or $10 \mu \mathrm{g}$ ). Histology and $N$-methyl-D-aspartic acid (NMDA) receptor labeling by ${ }^{3} \mathrm{H}-\mathrm{MK}-801$ in the pups cortices were studied. Short-term-alcohol-exposed pups had normal body and brain weights at birth, but their body growth was retarded postnatally. Ibotenic acid induced similar neuronal migration impairments in control and alcohol-exposed pups (nodular heterotopia in the white matter and/or deep cortical layers, subpial ectopia, and micro- or polymicrogyria). The size of lesions induced by $100 \mathrm{ng}$ ibotenic acid was increased in alcoholexposed pups; the $10 \mu \mathrm{g}$ dose was lethal. The density of ${ }^{3} \mathrm{H}$ -
\end{abstract}

\section{ABSTRACT}

MK-801 binding sites was similar in the three groups, indicating that exacerbated ibotenic acid excitotoxicity in alcohol-exposed pups did not result from increased NMDA receptor density. This study shows that alcohol exposure at levels that do not induce neuron migration disorders is sufficient to enhance the effects of the hypoxia-ischemia mimicking effects of ibotenic acid. (Pediatr Res 57: 287-293, 2005)
Abbreviations
ARND, alcohol-related neurodevelopmental disorders
FAS, fetal alcohol syndrome
GABA, gamma-aminobutyric acid
GFAP, glial fibrillary acidic protein
${ }^{\mathbf{3}} \mathbf{H}-\mathbf{M K}-\mathbf{8 0 1}$, tritiated dizocilpine
NeuN, neuronal nuclear antigen
NGF, nerve growth factor
NR2B, NMDA receptor subunit encoded by the GRIN-2B gene
NMDA, $N$-methyl-D-aspartic acid
PAF, platelet-activating factor

Alcohol is the main neurotoxin implicated in mental retardation in infancy. Maternal consumption of alcoholic beverages during pregnancy produces a broad spectrum of dosedependent toxic effects in the fetus. Two main clinical variants have been described, namely, ARND and FAS (1-3).

Alcohol exposure in early gestation may cause alterations in embryogenesis such as incomplete neural tube closure, corpus callosum agenesis, and microcephalus $(4,5)$. FAS is characterized by growth retardation, brain hypotrophy, and dysmorphol-

Received January 8, 2004; accepted July 9, 2004.

Correspondence: Philippe Leroux, Ph.D., UPRES EA 2122, Faculty of Medicine and Pharmacy, University of Rouen, 22 Boulevard Gambetta, F-76183, Rouen, France; e-mail: philippe.leroux@univ-rouen.fr

Supported by the Institut de Recherches scientifiques sur les Boissons (IREB), Paris, France, and the Région Haute-Normandie.

DOI: 10.1203/01.PDR.0000148712.30716.9D ogy, with or without mental retardation (6). Cognitive impairments without detectable dysmorphology may occur after mild alcohol exposure in utero (7). There is general agreement that there is no threshold for alcohol to have teratological effects (8). Migration disorders manifest as an arrest in neuroglial cell migration in the white matter or deep gray matter (heterotopia) (9) and loss of cortex laminar organization (10). The effects of alcohol on cerebral development vary with many factors, including plasma alcohol levels, the developmental stage of the fetus, the duration and frequency of alcohol intake, and the genetic background.

Alcohol affects glutamate NMDA and GABA-A receptor activities, reducing NMDA-evoked $\mathrm{Ca}^{2+}$ currents (11) and potentiating GABA-A Cl${ }^{-}$currents in adults (12). Neuronal migration is tightly controlled by NMDA receptors (13), and mice with NMDA receptor dysfunction exhibit severe neuronal 
migration abnormalities (14). Acute exposure to high-dose alcohol induces neuronal apoptosis in rat neonates through NMDA receptor inhibition and leads to loss of brain mass (15). Nevertheless, the neurodevelopmental damage caused by alcohol cannot be ascribed solely to effects on NMDA and GABA-A receptors. The impairment of neuronal migration, the corpus callosum agenesis, and the microcephaly observed in FAS probably result from effects on the glia (16). In utero alcohol exposure affects radial glia morphology $(10,17)$, as well as GFAP expression by astrocytes (18).

In a previous study, we showed that ibotenic acid provoked neuronal migration disorders through NMDA activation (19). The heterotopia and subpial ectopias corresponding to migration beyond the normal target to the superficial cortical layer I were somehow reminiscent of those seen in FAS (20). Alcohol exposure was known to amplify NMDA receptor expression $(21,22)$ and activity $(23)$. Hence, the present study was designed to determine whether in utero alcohol exposure could be followed by increased sensitivity to NMDA receptor-mediated neuronal migration disorders.

\section{MATERIALS AND METHODS}

Animals. Golden hamsters (100-180 g) were purchased from Janvier (Le Genest, France) and bred in the laboratory. The animals had free access to food and water or alcohol solution and were subjected to a $12 \mathrm{~h} / 12 \mathrm{~h}$ light/dark cycle. Males and females were housed together for $3 \mathrm{~d}$. Nonalcohol-exposed pups were obtained from water-drinking dams $(n=17)$. One group of dams was subjected to short-term alcohol exposure started $5 \mathrm{~d}$ after removal of the males (on d 5-8 of pregnancy, which lasts $17 \mathrm{~d}$ in hamsters) and continued until the pups were killed on postnatal d 5 (P5). The alcohol was added to the dams' drinking water in a concentration of $7 \%(\mathrm{vol} / \mathrm{vol})(n=36), 10 \%(n=$ $5)$, or $12 \%(n=3)$. In another group $(n=9)$, long-term alcohol exposure was obtained by giving female hamsters $7 \%$ alcohol in their water for at least 3 mo (up to $5 \mathrm{mo}$ ) before mating and subsequently until the pups were killed on P5. The excitotoxic effects of ibotenic acid $(1 \mathrm{ng}$ to $10 \mu \mathrm{g})$ were studied in newborns from unexposed control dams, short-term-exposed dams, and longterm-exposed dams. Newborn were used within $6 \mathrm{~h}$ after birth, a period noted $\mathrm{P} 0$, then the age was counted as P1 to P5.

Drinking behavior and plasma alcohol kinetics. In eight animals, liquid intake was determined for up to $14 \mathrm{~d}$ using a monitoring device (Columbus Instruments, Columbus, $\mathrm{OH}$ ) that recorded the number of laps per 10-min period. Two groups were studied successively in the four-compartment device, each composed of two water-drinking and two alcohol (7\%) drinking animals. The liquid consumption per day was also recorded. In the animals given water with $7 \%$ alcohol, the maximum volume ingested in 10 min was $5.2 \pm 0.7 \mathrm{~mL}$. Therefore, we administered $3 \mathrm{~mL}$ or $5 \mathrm{~mL}$ of $7 \%$ alcohol by gastric gavage to measure plasma alcohol kinetics in separate nonpregnant females with a mean weight of $121 \pm 9 \mathrm{~g}$. Ketamine (Imalgene, Merial Laboratory, Lyon, France) $5 \mathrm{mg} / \mathrm{kg}$ was used to anesthetize the animals. Blood collected from the venous sinus of the eye after 15, 30, 60, $180 \mathrm{~min}$, and $24 \mathrm{~h}$ was centrifuged, and the plasma was frozen until alcohol assay. In addition, 36 blood samples were collected using the same procedure from freely drinking females at various times during the day; 20 samples between 0700 and $1200 \mathrm{~h} ; 16$ samples between 1200 and $1600 \mathrm{~h}$.

Alcohol assay. Alcohol levels in blood samples from freely drinking females or females given $7 \%$ alcohol by gastric gavage were assayed using the Emit II Plus device (Dade Behring, Paris, France), in the biochemistry department of the university hospital in Rouen, which is accredited to perform alcohol assays requested by the justice department. A pregnant female was given $5 \mathrm{~mL}$ of $7 \%$ alcohol by gastric gavage on E17 (full term). Thirty minutes later, alcohol levels were measured concomitantly in the dam's plasma and brain and in the brains and placentas of six fetuses. For tissue ethanol assays, brain tissues were homogenized by ultrasonication in saturated $\mathrm{NaH}_{2} \mathrm{PO}_{4}$ solution. After centrifugation, the underlying liquid phase was collected, filtered, and frozen at $-80^{\circ} \mathrm{C}$ until alcohol assay, which was done as for the blood samples.

Energy intake estimation. Liquid and dry food intakes were measured in 4 dams given water and in 12 dams given $7 \%$ alcohol in water. Dams were allowed free access to rodent laboratory chow for pregnant animals $(11.6 \mathrm{~kJ} / \mathrm{g})$ (Special Diets Services, Vigny, France). The energy content of alcohol was considered to be $20 \mathrm{~kJ} / \mathrm{g}$. Daily chow intake was weighted for $4 \mathrm{~d}$ in 12 females exposed to alcohol for $7 \mathrm{~d}$ before and in 4 control dams.

Excitotoxic lesions. All protocols and procedures complied with the guidelines established by the Institut National de la Santé et de la Recherche Médicale (INSERM) for laboratory animals and were performed under the supervision of a licensed expert (P.L., license number: 76.A.16). Excitotoxic lesions were induced in pups from unexposed dams (controls), short-termexposed dams, and long-term-exposed dams. The excitotoxic lesions were induced in the somatosensory cortex as previously described (19) by injecting ibotenic acid (1 ng to $10 \mu \mathrm{g}$ ) (Sigma Chemical Co., L'Isles d'Abeau Chesnes, France) dissolved in $2 \mu \mathrm{L}$ of sterile PBS, $\mathrm{pH} 7.4$, into the cortex, using a semistereotactic method, under isoflurane anesthesia. Ibotenic acid is a glutamatergic agonist at NMDA and metabotropic receptors, although its toxicity in neonatal hamster cortex is specifically blunted by the NMDA receptor antagonist AP7 (19). Ibotenic acid injection was performed within $6 \mathrm{~h}$ after birth and required separation from the dam for no longer than $10 \mathrm{~min}$. The pups were killed on P5 and their brains were prepared for histology, as previously described (19). Excitotoxic lesions were identified by light microscope examination of cresyl violet-stained $10-\mu \mathrm{m}$ serial sections. Lesion size was estimated as the rostrocaudal length of the lesion (number of abnormal sections multiplied by $10 \mu \mathrm{m}$ ). Microscopy was performed by an expert unaware of the group assignment of the animals.

Heterotopic neuronal cells were identified by immunohistochemical labeling of nuclear neuronal specific antigen (NeuN, Chemicon, Cergy, France). Sections were exposed to microwaves ( $10 \mathrm{~min}$ in $0.1 \mathrm{M}$ citrate buffer, $\mathrm{pH}$ 6.0) then rinsed in $0.1 \mathrm{M}$ PBS $(\mathrm{pH} 7.4)$ containing gelatin $(2 \mathrm{~g} / \mathrm{L})$ and Triton $\times 100$ $(0.4 \%)$ (blocking buffer). The sections were incubated with monoclonal antiNeuN mouse Ig $(50 \mu \mathrm{g} / \mathrm{mL})$ in blocking buffer for $1 \mathrm{~h}$ at room temperature and finally subjected to indirect immunoperoxidase staining using a biotinylated horse anti-mouse $\operatorname{IgG}(1.5 \mathrm{mg} / \mathrm{mL}$ for $45 \mathrm{~min})$, streptavidin peroxidase ( $\mathrm{ABC}$ kit, Vector, Abcys, Paris, France), and diamino-benzidine plus urea-peroxide (Sigma Chemical Co.) as the substrate. Controls were performed by omitting the primary antibody.

Density of ${ }^{3} \mathrm{H}-\mathrm{MK}-801$ binding sites. NMDA receptors were labeled in frozen brain sections from P0 pups and their dams, using ${ }^{3} \mathrm{H}-\mathrm{MK}-801$ binding as previously described (14). Binding was detected and quantified using a radio-imager (Biospace, Paris, France). ${ }^{3} \mathrm{H}-\mathrm{MK}-801$ concentrations in the media were $4.7 \mathrm{nM}$ and $8.8 \mathrm{nM}$ for adult and neonate sections, respectively. ${ }^{3} \mathrm{H}-\mathrm{MK}-801$ binding was measured in four or more brain sections in two to six animals per group. Sections were collected between the interhemispheric junction of anterior commissure and the rostral limit of hippocampus. In neonates, the binding was measured over whole brain sections whereas in adults it was measured selectively in the cortex.

Statistical analyses. Mean \pm SE values of daily liquid volume intakes were compared using the student $t$ test. One-way or two-way ANOVA were used to evaluate dose-dependent effects of ibotenic acid and/or alcohol exposure on lesion size, body weights, and brain weights on P5. Between-group comparisons of ibotenic acid effects were achieved using the Newman-Keuls test. The nonparametric Kruskal-Wallis test was used to compare ${ }^{3} \mathrm{H}-\mathrm{MK}-801$ bindingsite densities in P0 brains and adult brains. The rates of occurrence of each lesion type were compared in pup groups from water- and alcohol-drinking dams using the two-sided Fisher exact test.

\section{RESULTS}

Drinking behavior. Female hamsters drank the alcoholwater mixtures readily, so that addition of a flavoring agent to mask the alcohol taste was unnecessary. The net spontaneous volume intake was $50 \%$ higher in the group receiving $7 \%$ alcohol than in the group with no alcohol. With the higher alcohol concentrations (10\% and 12\%), the animals drank smaller volumes, so that the intake of alcohol was similar to 
that seen with the $7 \%$ concentration. The daily volume intake was significantly greater with long-term exposure (3-5 mo) than with short-term exposure to $7 \%$ alcohol (Table 1). Two patterns of drinking behavior over the 24-h cycle were seen, an episodic pattern (usually two to five episodes of drinking during the night), with intervals of abstinence, and a more regular pattern of drinking toward the end of the light period and during the dark period (Fig. 1). These two patterns were observed alternately in the same individuals, with free access to water or to $7 \%$ alcohol.

Plasma alcohol levels. Of 36 plasma alcohol assays done in samples from animals drinking 7\% ethanol, 21 were below the detection limit $(10 \mathrm{mg} / \mathrm{dL}), 13$ showed low values $(10-40$ $\mathrm{mg} / \mathrm{dL}$ ), and 2 showed values $>120 \mathrm{mg} / \mathrm{dL}$. In animals given $3 \mathrm{~mL}$ or $5 \mathrm{~mL}$ of $7 \%$ alcohol by gastric gavage, the maximum concentration was observed after $30 \mathrm{~min}$. In the group given 5 $\mathrm{mL}$, plasma alcohol levels were around $200 \mathrm{mg} / \mathrm{dL}$ for $60 \mathrm{~min}$ and were still $>100 \mathrm{mg} / \mathrm{dL}$ after $3 \mathrm{~h}$. In the two animals given $3 \mathrm{~mL}$ of $7 \%$ alcohol, plasma alcohol levels expressed as the proportion of the volume of alcohol administered were lower at all time points than in the group given $5 \mathrm{~mL}$ of $7 \%$ alcohol. Plasma alcohol levels in the group given $3 \mathrm{~mL}$ were within the range of values observed in some spontaneously drinking animals, the other having probably not drank for several hours when blood sampling were done. Alcohol was undetectable in plasma $24 \mathrm{~h}$ after gavage (Table 2).

Thirty minutes after gavage, the plasma alcohol level in the pregnant female was $139 \mathrm{mg} / \mathrm{dL}$; tissue levels were $692 \pm 9$ $\mu \mathrm{g} / \mathrm{g}$ in the dam's brain, $625 \pm 32 \mu \mathrm{g} / \mathrm{g}$ in the fetal brains, and $422 \pm 36 \mu \mathrm{g} / \mathrm{g}$ in the placentas, respectively.

Effect of alcohol exposure on energy intake and body weight at the end of gestation. We monitored the total energy intake in animals given short-term 7\% alcohol and in controls. The short-term-exposed animals reduced their dry food consumption in proportion to the energy provided by the alcohol, so that their total energy intake was not statistically different from that in controls (Table 3). No difference was found in energy intake between pregnant and nonpregnant females (not shown). Alcohol intake affected neither the body weight increase in dams during the last $9-12 \mathrm{~d}$ of gestation nor the size of the litters (Table 3).

Effects of alcohol exposure on pup growth and brain weight. Pup birth weight was not affected by short-term alcohol exposure in utero. Conversely, a two-way ANOVA study shows that alcohol exposure and ibotenic acid (100 ng) injections affected postnatal growth very significantly $[\mathrm{F}(1,50)=$ $32 ; p<0.001]$. The posthoc Newman-Keuls test revealed that among pups given intracortical PBS on $\mathrm{P} 0$, those exposed to

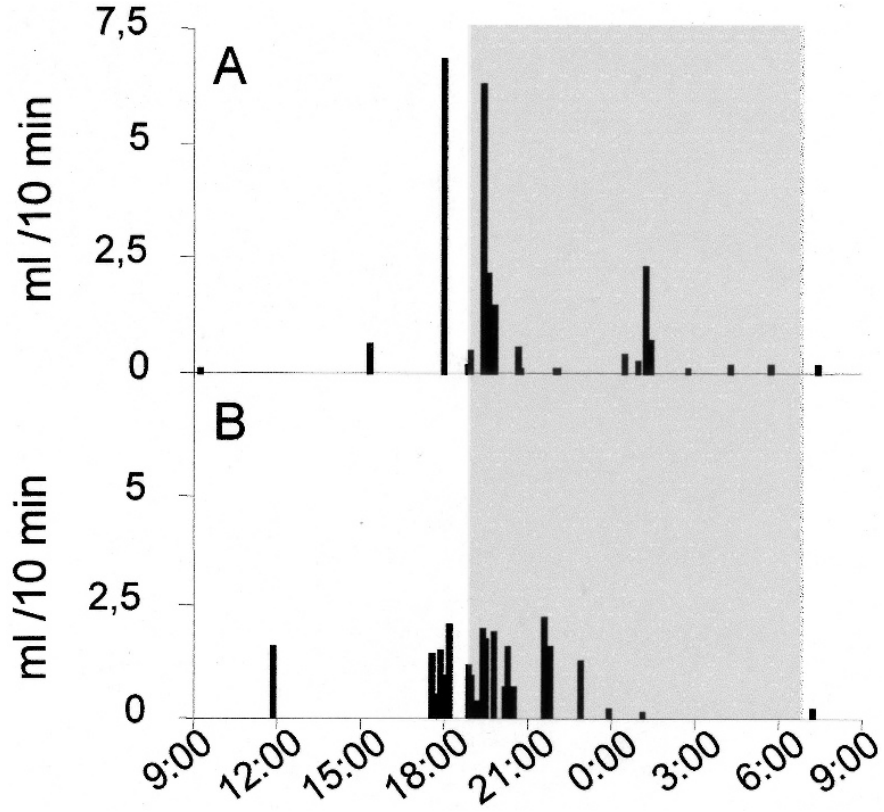

Figure 1. Drinking behavior profile over two 24-h cycles in a female given $7 \%$ alcohol. (A) Episodic intake; $(B)$ more regular moderate intake. The gray zone indicates the 12 -h dark period.

Table 2. Plasma alcohol levels $(\mathrm{mg} / \mathrm{dL})$ in female hamsters given $7 \%$ alcohol by intragastric gavage $(3 \mathrm{~mL}, 210 \mathrm{mg}$; or $5 \mathrm{~mL}, 350$

\begin{tabular}{cccccc}
\multicolumn{7}{c}{$m g)$} \\
\hline Alcohol dose & $15 \mathrm{~min}$ & $30 \mathrm{~min}$ & $60 \mathrm{~min}$ & $180 \mathrm{~min}$ & $24 \mathrm{~h}$ \\
\hline $210 \mathrm{mg}(n=2)$ & - & $92-116$ & $48-92$ & $10-36$ & n.d. \\
$350 \mathrm{mg}(n=4)$ & $205 \pm 38$ & $225 \pm 6$ & $191 \pm 23$ & $134 \pm 20$ & n.d.
\end{tabular}

n.d., Not detectable.

Table 3. Energy intake ( $\mathrm{kJ} / \mathrm{d} / 100 \mathrm{~g}$ body weight), body weight, and litter size in dams given water or short-term $7 \%$ alcohol

\begin{tabular}{lcl}
\hline \multicolumn{1}{c}{ Energy source } & Water & \multicolumn{1}{c}{ Alcohol } \\
\hline Chow & $82.5 \pm 4.9$ & $53.7 \pm 4.0$ \\
Alcohol & - & $21.1 \pm 2.2$ \\
Total & $82.5 \pm 4.9(n=4)$ & $74.8 \pm 4.6(n=12)$ \\
\hline Initial body weight & $124 \pm 9$ & $123 \pm 13$ \\
Final body weight & $148 \pm 8$ & $147 \pm 11$ \\
Litter size & $6.2 \pm 0.8(n=12)$ & $5.9 \pm 0.9(n=6)$ \\
\hline
\end{tabular}

alcohol had significantly lower body weights on P5 $(p<$ 0.001), compared with pups not exposed to alcohol (Table 4). Intracortical ibotenic acid injection (100 ng) was also associated with growth retardation on P5 in litters from unexposed dams $[\mathrm{F}(1,50)=35 ; p<0.001]$ (Table 4). A significant interaction between alcohol exposure and ibotenic acid was

Table 1. Fluid intake ( $\mathrm{mL} / \mathrm{d} / 100 \mathrm{~g}$ body weight) and alcohol consumption $(\mathrm{g})$ in female hamsters given water, short-term alcohol, or long-term alcohol

\begin{tabular}{|c|c|c|c|c|c|}
\hline & Water & $\begin{array}{l}\text { Short-term } \\
\text { alcohol 7\% }\end{array}$ & $\begin{array}{l}\text { Short-term } \\
\text { alcohol } 10 \%\end{array}$ & $\begin{array}{l}\text { Short-term } \\
\text { alcohol } 12 \%\end{array}$ & $\begin{array}{c}\text { Long-term alcohol } \\
7 \%\end{array}$ \\
\hline Fluid intake $(n)$ & $11.9 \pm 1.5(10)$ & $17.8 \pm 1.1 *(30)$ & $14.5 \pm 2.1(5)$ & $11.8 \pm 0.6(3)$ & $23.0 \pm 1.6^{* *}, \dagger(8)$ \\
\hline Alcohol intake (g) & - & 1.00 & 1.16 & 1.14 & 1.29 \\
\hline
\end{tabular}

$n$, number of females.

$* p<0.01 ; * * p<0.001$ compared with water; $\dagger p<0.02$ compared with short-term alcohol (7\%) exposure. 
Table 4. Effect of short-term 7\% alcohol exposure in dams on PO and P5 body weights $(\mathrm{g})$ and on P5 brain weights (mg) of pups given intracortical PBS or Ibo (100 ng) at birth

\begin{tabular}{|c|c|c|c|c|}
\hline & \multicolumn{2}{|c|}{ Water } & \multicolumn{2}{|c|}{ Short-term alcohol 7\% } \\
\hline & PBS & Ibo & PBS & Ibo \\
\hline Birth weight (g) & $2.45 \pm 0.9(n=13)$ & $2.16 \pm 0.08(n=10)$ & $2.33 \pm 0.06(n=15)$ & $2.19 \pm 0.51(n=19)$ \\
\hline Body weight on P5 (g) & $7.33 \pm 0.10(n=13)$ & $5.39 \pm 0.13^{*}(n=10)$ & $5.44 \pm 0.35^{*}(n=13)$ & $5.01 \pm 0.12(n=17)$ \\
\hline Brain weight on P5 (g) & $206 \pm 6(n=12)$ & $194 \pm 6(n=10)$ & $219 \pm 4(n=13)$ & $205 \pm 5(n=17)$ \\
\hline
\end{tabular}

$* p<0.001$ vs PBS-injected pups born to dams given water.

observed $[\mathrm{F}(1,50)=14 ; p<0.001]$. The posthoc NewmanKeuls comparison of ibotenic acid- or PBS-injected pups in alcohol exposed animals did not show an additive effect (Table 4).

Alcohol exposure did not result in reduced brain weight in animals injected with PBS. Conversely, the two-way ANOVA study indicated that brain weight was decreased in animals injected with $100 \mathrm{ng}$ ibotenic acid $[\mathrm{F}(1,48)=5.5 ; p<0.05]$. The effect did not reached statistical significance in either water or short-term-alcohol-exposed groups according to posthoc Newman-Keuls analysis. The brain weights were not diminished in proportion to body weight decreases in single experimental groups (Table 4). Long-term alcohol exposure of female hamsters caused dramatic alterations in fertility and maternal behavior. The consequence was that many pups from these females died before P5. Thus, we did not perform PBS injections in this group. No study on body weight and brain weight was performed on these animals.

Effects of alcohol exposure on ibotenic acid-induced brain lesions in pups at birth. Intrapallial PBS injection in P0 control hamsters caused minimal histologic alterations $(20 \mu \mathrm{m})$ in one of the seven injected pups. In pups from dams exposed to alcohol (7\%), PBS injection on P0 caused lesions with a similar rate of occurrence (2/14 pups) and size $(30 \pm 10 \mu \mathrm{m})$ as in the controls.

Intrapallial ibotenic acid injection on P0 to pups from unexposed dams induced cytoarchitectural disorganization related to neuronal migration abnormalities, as previously described (19) (Fig. 2). Immunohistochemical labeling of NeuN or GFAP antigens in sections with deep heterotopia or subpial ectopia showed that cells in abnormal locations exhibited NeuN staining, although with variable intensity (Fig. 2, $I$ and $J)$. No typical GFAP-positive astrocytes were detected in heterotopic foci. Ibotenic acid-induced lesion types were similar in brains from pups born to unexposed and exposed (7\% alcohol) dams. On P5, postmigratory neurons were found in the white matter or the deep cortical layers (heterotopia, Fig. 2, $A-C)$ and in the superficial molecular layer in a subpial position (ectopia, Fig. 2, $E$ and $F$ ). Abnormal gyri developed after ibotenic acid injection either when migrating neurons stopped in a deep heterotopic location (Fig. $2 \mathrm{C}$ ) or when postmigratory neurons in layers $\mathrm{V}$ and VIa were destroyed (Fig. $2 H$ ). Cell loss was often noted near heterotopic foci and near gyri (Fig. 2, $B$, $D, I$, and $J$ ). Lesions reminiscent of polymicrogyria in humans were seen in association with hemisphere atrophy (Fig. 2, G and $H$ ).

The rates of occurrence of neuronal heterotopia, subpial ectopia, and microgyria were evaluated separately (Table 5). Two or three of these abnormalities were present in most
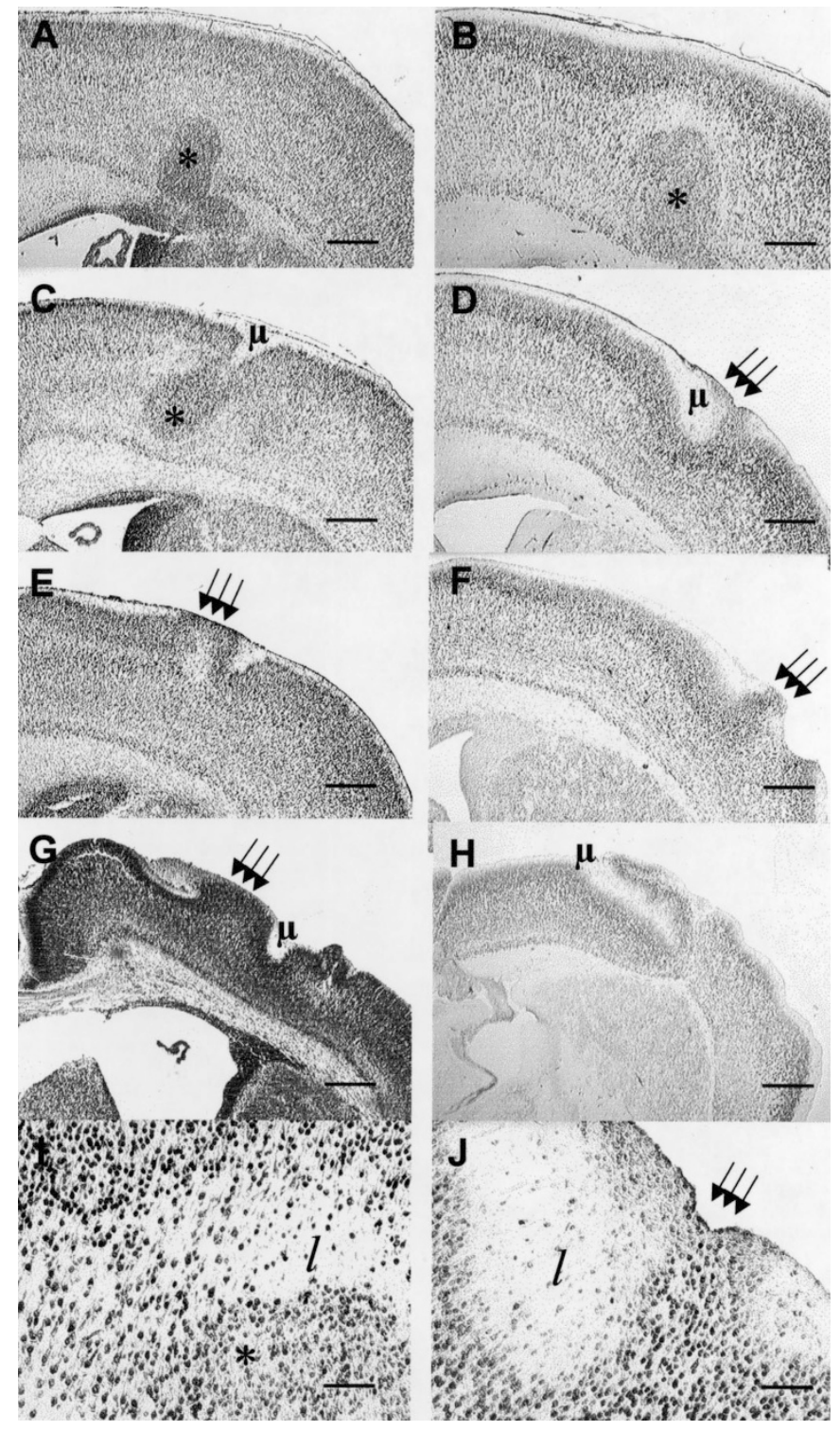

Figure 2. Cresyl violet staining $(A, C, E, G)$ and NeuN immunohistology ( $B$, $D, F, H, I, J)$ of pup brain sections $5 \mathrm{~d}$ after intrapallial ibotenic acid (Ibo) injection. ( $A-F, I, J$ : pups from dams given water; $G$ and $H$ : pups from dams given short-term $7 \%$ alcohol. $A, B$ : nodular neuronal heterotopia after $1 \mathrm{ng}$ Ibo. $C$ : nodular heterotopia with microgyria after $10 \mu \mathrm{g}$ Ibo. $D$ : microgyria and subpial ectopia in the molecular layer after $1 \mathrm{ng}$ Ibo. $E$ : subpial ectopia after $100 \mathrm{ng}$ Ibo. $F$ : Subpial ectopia after $1 \mathrm{ng}$ Ibo. $G$ and $H$ : polymicrogyria after $100 \mathrm{ng}$ Ibo. $I$ and $J$ : enlargements of $B$ and $D$. *Indicates nodular heterotopia; $\mu$, microgyria; $l$, neuronal loss; arrows, subpial ectopia. Bar $=200 \mu \mathrm{m}$ in $A-F$, $360 \mu \mathrm{m}$ in $G$ and $H$, and $50 \mu \mathrm{m}$ in $I$ and $J$.

individuals, so that the sum of the occurrence rates exceeded $100 \%$ in all groups. Subpial ectopia was absent in pups born to unexposed dams and injected with $10 \mu \mathrm{g}$ of ibotenic acid 
Table 5. Effect of intrapallial Ibo injection on PO on the cortical cytoarchitecture alterations seen on P5 in pups from dams given water, short-term 7\% alcohol, or long-term 7\% alcohol

\begin{tabular}{ccccc}
\hline $\begin{array}{c}\text { Alcohol } \\
(7 \%)\end{array}$ & Ibo (N/n) & $\begin{array}{c}\text { Nodular } \\
\text { heterotopia }\end{array}$ & $\begin{array}{c}\text { Subpial } \\
\text { ectopia }\end{array}$ & $\begin{array}{c}\text { Microgyria or } \\
\text { polymicrogyria }\end{array}$ \\
\hline 0 & $1 \mathrm{ng}(18 / 5)$ & $56 \%$ & $56 \%$ & $66 \%$ \\
0 & $100 \mathrm{ng}(14 / 6)$ & $86 \%$ & $86 \%$ & $100 \% \ddagger$ \\
0 & $10 \mu \mathrm{g}(8 / 2)$ & $100 \%$ & $0 *, \dagger$ & $100 \%$ \\
\hline Short-term & $1 \mathrm{ng}(9 / 2)$ & $56 \%$ & $56 \%$ & $33 \%$ \\
Short-term & $100 \mathrm{ng}(29 / 9)$ & $72 \%$ & $\begin{array}{c}58 \% \\
\text { lethal }(100 \%)\end{array}$ & $90 \% \S$ \\
Short-term & $10 \mu \mathrm{g}(14 / 3)$ & & $71 \%$ & $86 \%$ \\
\hline Long-term & $100 \mathrm{ng}(7 / 3)$ & $100 \%$ &
\end{tabular}

$(N / n)$ number of brains examined per group/number of litters.

* Significantly different from $1 \mathrm{ng}(p<0.01)$ Ibo in pups from dams given water.

$\dagger$ Significantly different from $100 \mathrm{ng}(p<0.001)$ Ibo in pups from dams given water.

$\ddagger$ Significantly different from $1 \mathrm{ng}(p<0.05)$ Ibo in pups from dams given water.

$\S$ Significantly different from $1 \mathrm{ng}(p<0.05)$ Ibo in pups from dams given short-term $7 \%$ alcohol.

(Table 5). In contrast, the rate of neuronal heterotopia increased with the ibotenic acid dose in pups from unexposed and exposed dams, although the difference was not significant between $1 \mathrm{ng}$ and $10 \mu \mathrm{g}$ ibotenic acid in the unexposed groups ( $p=0.06$ by the Fisher two-sided test). In pups from dams chronically exposed to alcohol, deep heterotopia was consistently seen after injection of $100 \mathrm{ng}$ ibotenic acid. The rate of microgyria increased significantly in relation to the ibotenic acid dose in both the unexposed and the exposed groups (Table 5 ). No effect of alcohol was observed on lesion patterns induced by $1 \mathrm{ng}$ or $100 \mathrm{ng}$ ibotenic acid, whereas the $10-\mu \mathrm{g}$ dose was lethal in all the short-term-alcohol-exposed pups.

Conversely, alcohol affected lesion size (Fig. 3). In pups from unexposed dams, lesion size was dependent on the ibotenic acid dose $[\mathrm{F}(2,44)=5.1 ; p<0.001$ by one-way ANOVA]. Injection of PBS seldom produced very small lesions, size $<40 \mu \mathrm{m}$. Because all the pups from short-termalcohol-exposed dams died after intrapallial injection of the 10 $\mu \mathrm{g}$ ibotenic acid dose ( $n=14$ from three different litters), a two-way ANOVA was done from the 0 to $100 \mathrm{ng}$ ibotenic acid doses in unexposed and short-term-ethanol-exposed groups. The test revealed an interaction between the two parameters $[\mathrm{F}(2,92)=3.2 ; p=0.046]$. The posthoc Newman-Keuls analysis revealed that short-term alcohol significantly enhanced the size of ibotenic acid-induced lesions at the $100 \mathrm{ng}$ dose only (Fig. $3 A$ ). Lesion size in the water group injected with $10 \mu \mathrm{g}$ ibotenic acid was $750 \pm 78 \mu \mathrm{m}(n=8)$. The duration of dam exposure to alcohol significantly affected the effect of $100 \mathrm{ng}$ ibotenic acid $[\mathrm{F}(2,55)=8.8 ; p<0.001$ according to one-way ANOVA]. The posthoc Newman-Keuls analysis indicated that long-term exposure to alcohol was responsible for enhanced lesion size compared with unexposed and short-term-exposed groups (Fig. 3B).

Effects of alcohol exposure on ${ }^{3} \mathrm{H}-\mathrm{MK}-801$ binding-site density in PO and adult hamster brains. NMDA-receptor labeling by ${ }^{3} \mathrm{H}-\mathrm{MK}-801$ revealed higher binding-site densities in adults than in neonates, although incubation was performed
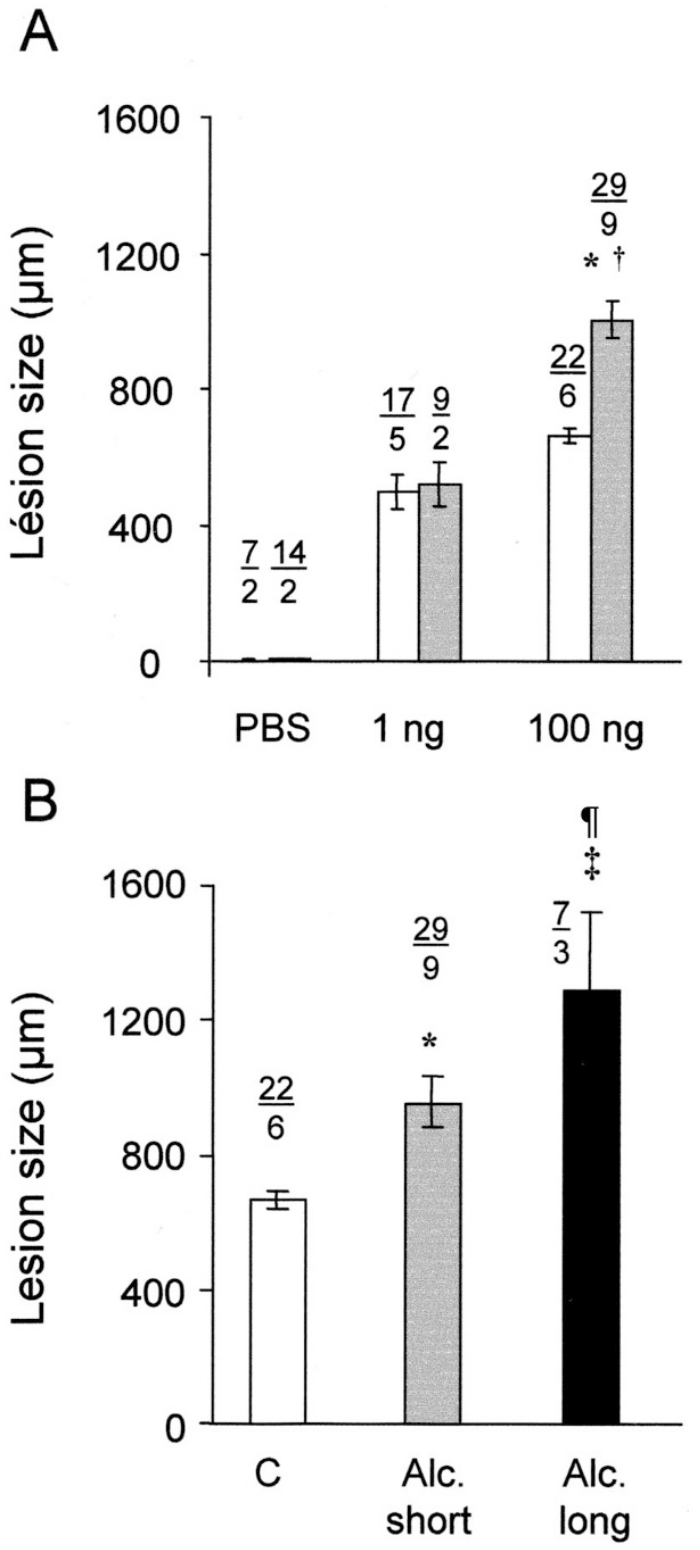

Figure 3. Effect of intrapallial ibotenic acid $(I b o)$ injected to newborn $(P O)$ hamsters $(A)$, and effect of short-term (Alc. short) or long-term alcohol (Alc. long) on the size of lesions in newborn hamsters injected with $100 \mathrm{ng}$ ibotenic acid $(B)$. Brain lesions were evaluated on P5. Open bars: pups from unexposed dams; gray bars: pups from dams with short-term exposure to $7 \%$ alcohol; and black bar: pups from dams with long-term exposure to alcohol. Symbols indicate statistically significant differences between groups evaluated using the Newman-Keuls test. $N / n$ over histograms indicate the number of brain examined per group and the number of litters of origin of these pups, respectively. ${ }^{*} p<0.05$ and ${ }^{\mathbb{T}} p<0.001 \mathrm{vs}$ effect of $100 \mathrm{ng}$ Ibo in pups from unexposed dams; $\uparrow p<0.001 v s$ effect of $1 \mathrm{ng}$ Ibo in pups from short-term-exposed dams; $\ddagger p<0.05 v s$ effect of $100 \mathrm{ng}$ Ibo in pups from short-term-exposed dams. $C$, Controls.

with a lower radioligand concentration. Compared with controls from unexposed dams, ${ }^{3} \mathrm{H}-\mathrm{MK}-801$ binding-site density was $205 \%(p<0.05)$ in brain sections from short-termexposed dams and $167 \%$ in those from long-term-exposed dams (Fig. 4A). Conversely, ${ }^{3} \mathrm{H}-\mathrm{MK}-801$ binding-site densities were not significantly increased in pups from the dams exposed for short term or long term to alcohol (Fig. 4B). 

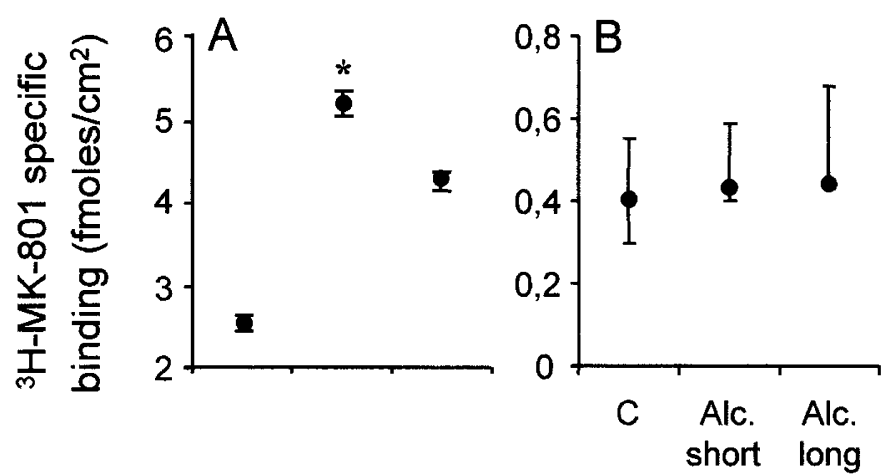

Figure 4. Effect of short-term (Alc. short) or long-term (Alc. long) prepartum alcohol exposure of female hamsters on ${ }^{3} \mathrm{H}-\mathrm{MK}-801$ binding-site density (median, Q1, Q3) in cerebral cortex and telencephalon frozen sections from the dams $(A)$ and P0 pups $(B) . * p<0.05$ according to the Kruskal-Wallis nonparametric test $v s$ values in control females not exposed to alcohol and in their pups. C, Controls.

\section{DISCUSSION}

Neuronal migration is not yet completed in hamsters at birth. Therefore, exposure to excitotoxic insults on P0 impairs neuronal migration in the cortex in hamsters. Deep heterotopias are believed to result from premature cell migration arrest, whereas subpial ectopia result from migration beyond the normal target (19). In our study, these effects were strengthened when pups were antenatally exposed to alcohol. Many studies reported the effect of alcohol on the expression of the cell adhesion molecule N-CAM by neurons and consequences on neuron migration (24-27). Heterotopic clusters of neurons have been described in rats fed ethanol-containing diet resulting from altered cell cycle, i.e. decreased proliferating rate, prolonged sojourn of postmitotic neurons in the proliferation area, and delayed migration by several days $(9,28)$. In mice, alcohol exposure induced a premature radial glia transformation and disorganized cortical neuronal pattern $(10,17)$. In addition, neurons modify extracellular environment by degrading laminin (24). The latter effect is partly rescued by the NMDA receptor antagonist MK-801, indicating the involvement of glutamate NMDA receptor in neuronal migration. The LIS-1 gene associated with severely impaired neuronal migration and lissencephaly encodes the PAF acetyl-hydrolase that degrades PAF. This mediator plays a key role in neuronal migration since both over-activation of its receptors and disturbance of its synthesis results in neuronal migration disruption $(14,29)$. This effect is concomitant to impaired NMDA receptor function (14). Altogether, these data indicate that alcohol interferes with many molecular events that direct neuronal migration, and in particular with NMDA receptor activity.

Most of the acquired cerebral lesions have multifactorial origin needing at least one acute insult and a favorable genetic and epigenetic background. In the present model, we found that alcohol significantly exacerbated NMDA receptor-mediated migration disorders after mild exposure, although alcohol 7\% used alone during partial or full gestation period (and before) was not sufficient to mimic fetal alcohol-induced malformations observed in FAS at these doses and timing of exposition.
Moreover, brain weight was preserved when postnatal growth was impaired.

The plasma alcohol levels in animals given free access to a water-alcohol mixture, together with the level of alcohol in brain and the plasma kinetics in animals given alcohol by gastric gavage, indicate that fetal alcohol exposure was mild. When the dams drank episodically, their fetuses were exposed to alcohol peaks $(100-200 \mathrm{mg} / \mathrm{dL})$ for a few hours each day, during which brain alcohol concentrations reached $63 \mathrm{mg} / \mathrm{dL}$ (near $15 \mathrm{mM}$ ). These values were far below the toxicity thresholds associated with NMDA receptor-mediated apoptosis $(>200 \mathrm{mg} / \mathrm{dL}$ for several hours) (15) or NR2B protein phosphorylation $(>300 \mathrm{mg} / \mathrm{dL})$ after acute alcohol administration (30). When the dams had a pattern of regular drinking, the fetuses were exposed to lower concentrations that appeared to undergo faster detoxification. As the dams drank little or not at all for about $12 \mathrm{~h}$ per 24-h cycle (Fig. 1), the fetuses had daily alcohol-free periods. All dams alternated between episodic and regular drinking, suggesting that our model may mimic the human behavior of regular alcohol intake with sporadic binge drinking. Our finding that exposed neonates had no brain damage or brain weight decrease yet showed increased sensitivity to ibotenic acid, suggests that our model may mimic conditions of alcohol exposure associated with ARND in humans (7). The absence of spontaneous dysmorphology, microcephaly, or low birth weight in newborns indicates that shortterm alcohol exposure used was inappropriate to promote a FAS. Alcohol exposure modified tissue responses to high, but not to low doses of ibotenic acid, suggesting that different doses of ibotenic acid may recruit different effectors with different sensitivity to alcohol. Similar dose-dependent effects of ibotenic acid have been reported previously in P5 mice (31).

Chronic ethanol has been reported to enhance NMDAreceptor protein expression in adult rat cortex (21), as well as in the hippocampus of young rats (P14 and P28) exposed to alcohol in utero (22). We noted similar effects in the cortices of dams exposed to alcohol for $17 \mathrm{~d}$ but found no increase in ${ }^{3} \mathrm{H}-\mathrm{MK}-801$ binding in the cortex of their pups on P0 (the age selected for the ibotenic acid injury). The difference of effects was not due to distinct bioavailability of alcohol, inasmuch as we observed the same brain concentration in the dam and its fetuses. A previous study showed that in utero and postnatal alcohol exposure in rats did not affect ${ }^{3} \mathrm{H}-\mathrm{MK}-801$ affinity (22), suggesting that the absence of alterations in ${ }^{3} \mathrm{H}-\mathrm{MK}-801$ binding-site density in our hamster model was indicative of an absence of alteration in NMDA receptor density.

Ibotenic acid (100 ng) produced larger brain lesions in pups from alcohol-exposed dams than in those from unexposed dams. The possibility that NMDA receptor activity was enhanced despite the absence of an increase in NMDA receptor density has previously been reported in vitro (23). Alternatively, the potentiating effect of alcohol exposure on ibotenic acid toxicity in newborns may result from alcohol effects on their dams. The enhancement of ibotenic acid toxicity in pups from chronically alcohol drinking females indicates that chronic alcohol modifies the physiology of pregnancy that in turn result in enhanced vulnerability of pups brains to exogenous injury (i.e., hypoxia-ischemia). The decreased postnatal 
growth in pups from short-term-alcohol-exposed dams was perhaps related to alcohol-induced changes in maternal behavior or milk production. Although alcohol exposure did not modify the energy intake of the dams, the protein intake was diminished by $35 \%$. Protein deficiency could in part be responsible for the effects of alcohol exposure observed inasmuch as it has been shown to have effects on brain maturation in newborn rats (32). Alcohol exposure in utero or during lactation also affects folic acid intestinal absorption and reduces its concentration in milk (33). Reduced folic acid intake would be expected to alter NMDA-mediated neurotransmission via homocysteine accumulation (34). Potentiation of the effects of NMDA activation after in utero alcohol exposure may also be a consequence of fetal hypoxia and impaired antioxidant defenses (35).

In conclusion, alcohol exposure in utero was associated with exacerbated toxicity of ibotenic acid in newborn hamsters, indicating that alcohol exposure during development was deleterious even in the absence of brain malformation. Alcohol is one of the most widely abused substances in pregnant women. This study suggests that even modest alcohol levels may increase the vulnerability of the fetal cortex to the large variety of agents capable of triggering an excitotoxic cascade (36). The absence of effect of such exposure on NMDA receptor density lets unsolved the question of the biochemical targets of alcohol in the dam/fetus-neonate couple.

Acknowledgments. The authors thank Prof. Jean Costentin for allowing us to use the radio-imager and the drinking monitoring device, Dr. Jean François Ménard for his help in statistical analyses, M. Jean Paul Henry for his skillful handling of the animals, and Ms. Cathy Vendeville for her expert technical assistance.

\section{REFERENCES}

1. Lemoine P, Harrousseau H, Borteyru J, Menuet J 1968 Les enfants de parents alcooliques: anomalies observées: à propos de 127 cas. Ouest Médical 25:476-482

2. Jones KL, Smith AW 1973 Recognition of the fetal alcohol syndrome in early infancy. Lancet 2:999-1001

3. Stratton K, Howe C, Battaglia F (eds) 1996 Fetal Alcohol Syndrome: Diagnosis, Epidemiology, Prevention and Treatment. National Academy Press, Washington, DC, pp 4-21

4. Clarren SK, Alvord EC Jr, Sumi SM, Streissguth AP, Smith DW 1978 Brain malformations related to pre-natal exposure to ethanol. J Pediatr 92:64-67

5. Wisniewski K, Dambska M, Sher JH, Qazi Q 1983 A clinical neuropathological study of the fetal alcohol syndrome. Neuropediatrics 14:197-201

6. Clark CM, Li D, Conry J, Conry R, Loock C 2000 Structural and functional brain integrity of fetal alcohol syndrome in nonretarded cases. Pediatrics 105:1096-1099

7. Larroque B, Kaminski M, Dehaene P, Subtil D, Delfosse MJ, Querleu D 1995 Moderate prenatal alcohol exposure and psychomotor development at preschool age. Am J Public Health 85:1654-1661

8. Sampson PD, Streissguth AP, Bookstein FL, Barr HM 2000 On categorizations in analyses of alcohol teratogenesis. Environ Health Perspect 108:421-428
9. Miller MW 1993 Migration of cortical neurons is altered by gestational exposure to ethanol. Alcohol Clin Exp Res 17:304-314

10. Gressens P, Lammens M, Picard JJ, Evrard P 1992 Ethanol-induced disturbances of gliogenesis and neurogenesis in the developing murine brain: an in vitro and in vivo immunohistochemical and ultrastructural study. Alcohol Alcoholism 27:219-226

11. Lovinger D, White G, Weight FF 1989 Ethanol inhibits NMDA-activated ion current in hippocampal neurons. Science 243:1721-1724

12. Aguayo LG 1990 Ethanol potentiates the GABAA-activated $\mathrm{Cl}$ - current in mouse hippocampal and cortical neurons. Eur J Pharmacol 187:127-130

13. Komuro H, Rakic P 1993 Modulation of neuronal migration by NMDA receptors Science 260:95-97

14. Gressens P, Baes M, Leroux P, Lombet A, Van Veldhoven P, Janssen A, Vamecq J, Marret S, Evrard P 2000 Neuronal migration disorder in Zellweger mice is secondary to glutamate receptor dysfunction. Ann Neurol 48:336-343

15. Ikonomidou C, Bittigau P, Ishimaru MJ, Wozniak DF, Koch C, Genz K, Price MT, Stefovska V, Horster F, Tenkova T, Dikranian K, Olney JW 2000 Ethanol-induced apoptotic neurodegeneration and fetal alcohol syndrome. Science 287:1056-1060

16. Guerri C, Pascual M, Renau-Piqueras J 2001 Glia and fetal alcohol syndrome. Neurotoxicology 22:593-599

17. Miller MW, Robertson S 1993 Prenatal exposure to ethanol alters the postnatal development and transformation of radial glia to astrocytes in the cortex. J Comp Neurol 337:253-266

18. Guerri C, Renau-Piqueras J 1997 Alcohol, astroglia and brain development. Mol Neurobiol 15:65-81

19. Marret S, Gressens P, Evrard P 1996 Arrest of neuronal migration by excitatory amino acids in hamster developing brain. Proc Natl Acad Sci U S A 93:15463-15468

20. Barkovich AJ, Gressens P, Evrard P 1992 Formation, maturation and disorders of brain neocortex. Am J Neuroradiol 13:423-446

21. Kalluri HS, Mehta AK, Ticku MK 1998 Up-regulation of NMDA receptor subunits in rat brain following chronic ethanol treatment. Brain Res Mol Brain Res 58:221224

22. Naassila M, Daoust M 2002 Effect of prenatal and postnatal ethanol exposure on the developmental profile of mRNAs encoding NMDA receptor subunits in rat hippocampus. J Neurochem 80:850-860

23. Chandler LJ, Sutton G, Norwood D, Sumners C, Crews FT 1997 Chronic ethanol increases $N$-methyl-D-aspartate-stimulated nitric oxide formation but not receptor density in cultured cortical neurons. Mol Pharmacol 51:733-740

24. Liesi P 1997 Ethanol-exposed central neurons fail to migrate and undergo apoptosis. J Neurosci Res 48:439-448

25. Charness ME, Safran RM, Perides G 1994 Ethanol inhibits neural cell-cell adhesion. J Biol Chem 269:9304-9309

26. Hirai K, Yoshioka H, Kihara M, Hasegawa K, Sawada T, Fushiki S 1999 Effects of ethanol on neuronal migration and neural cell adhesion molecules in the embryonic rat cerebral cortex: a tissue culture study. Brain Res Dev Brain Res 118:205-210

27. Miller MW, Luo J 2002 Effects of ethanol and transforming growth factor beta (TGF beta) on neuronal proliferation and nCAM expression. Alcohol Clin Exp Res 26:1281-1285

28. Miller MW 1997 Effects of prenatal exposure to ethanol on callosal projection neurons in rat somatosensory cortex. Brain Res 766:121-128

29. Hirotsune S, Fleck MW, Gambello MJ, Bix GJ, Chen A, Clark GD, Ledbetter DH, McBain CJ, Wynshaw-Boris A 1998 Graded reduction of Pafah1b1 (Lis1) activity results in neuronal migration defects and early embryonic lethality. Nat Genet 19:333-339

30. Miyakawa T, Yagi T, Kitazawa H, Yasuda M, Kawai N, Tsuboi K, Niki H 1997 Fyn-kinase as a determinant of ethanol sensitivity: relation to NMDA-receptor function. Science 278:698-701

31. Hennebert $\mathrm{O}$, Marret S, Carmeliet P, Gressens P, Laquerrière A, Leroux P 2004 Role of tissue derived plasminogen activator (t-PA) in an excitotoxic mouse model of neonatal white matter lesions. J Neuropathol Exp Neurol 63:53-63

32. Gressens P, Muaku SM, Besse L, Nsegbe E, Gallego J, Delpech B, Gaultier C, Evrard P, Ketelslegers JM, Maiter D 1997 Maternal protein restriction early in rat pregnancy alters brain development in the progeny. Brain Res Dev Brain Res 103:21-35

33. Murillo-Fuentes ML, Murillo ML, Carreras O 2003 Effects of maternal ethanol consumption during pregnancy or lactation on intestinal absorption of folic acid in suckling rats. Life Sci 73:2199-2209

34. Ho PI, Ortiz D, Rogers E, Shea TB 2002 Multiple aspects of homocysteine neurotoxicity: glutamate excitotoxicity, kinase hyperactivation and DNA damage. J Neurosci Res 70:694-702

35. Abel EL, Hannigan JH1995 Maternal risk factors in fetal alcohol syndrome: provocative and permissive influences. Neurotoxicol Teratol 17:445-462 (erratum p 689)

36. Lipton SA, Rosenberg PA 1994 Excitatory amino acids as a final common pathway for neurologic disorders. N Engl J Med 330:613-622 